\title{
Public awareness and perception of Ghana's restrictive policy on fatty meat, as well as preference and consumption of meat products among Ghanaian adults living in the Kumasi Metropolis
}

Reginald A. Annan ${ }^{1 *}$, Charles Apprey ${ }^{1}$, Nana Kwasi Oppong ${ }^{1}$, Vanessa Petty-Agamatey ${ }^{1}$, Laudina Mensah ${ }^{1}$ and Anne Marie Thow ${ }^{2}$

\begin{abstract}
Background: The nutrition transition, currently observed across the world is driven by trade liberalization, urbanization and more sedentary lifestyles. Ghana implemented a restrictive policy to limit the availability and access to fatty meat in the 1990s. This paper sought to determine public awareness and perception of the policy's enforcement and impact, as well as the general attitude towards fatty meat, preference and consumption of meat types.

Method: A cross-sectional qualitative study was carried out among 377 adults, aged $\geq 18$ years, living in Kumasi Metropolis in the Ashanti Region, the second largest city in Ghana. An interviewer administered structured questionnaire and a food frequency questionnaire were used for data collection. Body composition parameters were determined with OMRON body composition analyser and blood pressure was measured with a digital sphygmomanometer.

Results: Majority of respondents were females (62.9\%), aged 18-35 years old (72.1\%) and were labourers, traders or teachers (52.5\%). Mean Body Mass Index of participants was $25.4 \mathrm{~kg} / \mathrm{m}^{2}$ and percent body fat was $30.4 \%$. Over half (58.9\%) of the participants were aware of, and most (81.2\%) supported the restrictions, although majority (57\%) thought there was low public awareness and less than 15\% felt the restrictions were well enforced. About 59.4\% believed the restriction could improve health, prevent disease and reduce deaths in the long-term. Two thirds $(67.1 \%)$ of the participants considered the fat content of the meat they bought and related fat to health problems (38.5\%) and obesity/stroke (7.4\%). Local meat products (meat produced in Ghana) were more preferred due to taste, freshness and healthiness than imported meat, but imported meat types (meat imported from other countries) were more available (56.5\%), cheaper (69.5\%) and regularly consumed than the local types.
\end{abstract}

Conclusion: There was a good level of public awareness, strong support and positive attitude towards Ghana's restrictive food standards on meat. Although preference for local meat type was greater, imported meat was more consumed due to cost and availability. Policies which limit access to, and availability of 'unhealthy' food should be implemented and enforced to improve the food environment in order to help address the growing obesity and non communicable disease trend.

Keywords: Fatty meat, Policy, Awareness, Consumption

\footnotetext{
* Correspondence: reggie@imtf.org; regyies@yahoo.com

'Department of Biochemistry and Biotechnology, College of Science, Kwame

Nkrumah University of Science and Technology, Private Mail Bag, University

Post Office, Kumasi, Ghana

Full list of author information is available at the end of the article
} 


\section{Background}

Many countries in sub-Saharan Africa including Ghana are currently faced with a double burden of malnutrition. On one end of the spectrum is undernutrition and related communicable diseases. The other end of the spectrum shows increasing prevalence of over nutrition and diet-related chronic diseases, and their associated deaths. Overweight and obesity are also common and it is possible to find overweight/obese adults with micronutrient deficiencies [1]. Cardiovascular diseases (CVD), including coronary heart disease (CHD), stroke and heart failure, are associated with 16.7 million deaths in the world every year [2], with $80 \%$ of all CVD deaths occurring in developing countries [3]. In Ghana, the national prevalence of hypertension was estimated at $28.7 \%$ [4]. Heart diseases and diabetes are on the rise in the region and figures for hypertension show levels ranging from 3\% in rural areas to more than $30 \%$ among urban dwellers [4]. Over $80 \%$ of the diabetics are of type 2, the form associated with obesity and physical inactivity. The WHO predicts increases in deaths from chronic diseases in low- and middle-income countries such as Ghana by 2030 [3].

Generally, dietary patterns characterized by high intake of fatty foods and refined carbohydrates, and a low consumption of fruits and vegetables are commonly reported to be strongly associated with metabolic risk factors for Cardiovascular Diseases (CVDs) and other chronic diseases $[1,5]$. Referred to as the nutrition transition, increased sedentariness and a shift in patterns of dietary intake towards more westernised foods [6], characterised by increased intake of saturated fat, salt and refined foods and decreased fruits, vegetables and fibre intake have been reported in many developing countries $[7,8]$. The nutrition transition has also contributed to an epidemiological transition characterised by increasing incidence of diet-related chronic diseases [9]. In Ghana, where the percentage of adults who consume sufficient amounts of fruits and vegetables is less than 5\%, increased consumption of foods high in fats, sugars and salt is a major contributor to the increasing prevalence of CVD currently observed [10]. Thus, although the threat of undernutrition remains, the observed trend shows that diet-related chronic disease incidence and its consequences require national interventions.

The changing pattern of dietary intake and lifestyle is spurred by urbanization, liberalisation of market and trade (especially in foods), physical inactivity and demographic shifts [11-13]. Consequently, international institutions, non-government agencies and academics have recommended the use of trade policy tools in food policies designed to improve the healthfulness of the food supply $[14,15]$. Recommendations include the use of food composition standards, reducing import tariffs on fruits and vegetables, maintaining high tariffs on unhealthy food imports and reducing imports of unhealthy foods.

The importation of cheap fatty cuts of meat has been identified in Africa and the Pacific as a contributor to both poor health (due to high fat intakes) and agricultural under-development $[16,17]$. Research in the Pacific has documented policies banning imported fatty meat products [18]. However, an ongoing challenge has been the development of non-discriminatory food policy tools that are consistent with international trade commitments. In the early 1990s, the Government of Ghana implemented an innovative policy to limit the amount of fat in meat products (both imported and domestically produced) in order to protect human health [19]. The policy sets the standards for fat content in meat at $25 \%$ or less for pork, mutton and beef, and $15 \%$ or less for poultry. To date, however, the only products banned under the standard have been imported turkey tails and chicken feet. In August 2013, a study to evaluate the process, outcomes and lessons learned from this innovative policy was carried out. Case study research and policy analysis methodologies were used to evaluate the policy, which enabled indepth assessment of the policy process and outcomes in Ghana, while enabling maximization of the usefulness of the case study for policy learning in other contexts. Based on the 'health policy analysis triangle', data on the process (agenda-setting, policy development, implementation), context, content and actors (local and international) for the policy as well as the policy outcomes were collected [20].

Findings of this evaluation showed that the policy had led to reduced availability of 'low quality' meats, especially turkey tails and chicken feet, which were mostly imported in the Ghanaian food supply [20]. It was expected that the reduction in 'low quality' meat availability would lead to consumption of 'healthier' meat types, especially the locally-produced ones, since these were deemed to have lower fat content and formed part of the context for the implementation of the policy. However, questions regarding public awareness and perception of this policy, in terms of its implementation, enforcement and impact, as well as general attitude towards fatty meat, preference for, and consumption of different meat types remained unanswered. Little is known about the contribution of fatty meat to the Ghanaian diet and the landscape, including the extent to which fatty meat is still a problem, 20 years after the implementation of the standards on fatty meats. The aim of this paper is to determine public awareness, perceptions and attitudes towards the policy's implementation, enforcement and impact. It also sought to assess the general attitude, preference and consumption of meat types by Ghanaian adults. 


\section{Methods}

The policy evaluation study was carried out in August 2013, using in-depth assessment of the policy process and outcomes in Ghana, including agenda-setting, policy development, implementation, context, content and actors (local and international) for the policy as well as the policy outcomes [20]. Twenty-seven (27) semi-structured interviews were conducted with policy makers in Trade, Health and Agriculture; Implementers in Ghana Standards Authority, Ghana Food and Drugs Authority, Animal Extension and Customs Excise and Preventive Service (CEPS); Traders and importers; and Agricultural producers. Also, broad contextual questions regarding the historical trade policy context, changes in food prices and agricultural production, and the perceived effect of food imports on agricultural production were delved into [20].

\section{Study design and population}

Data for this study were collected between February to April 2015 using a cross sectional qualitative design among adults, aged 18 years and above living in suburbs of Kumasi Metropolis, the second largest city of Ghana. This study sought to assess participants' awareness of the policy, what they thought the general awareness of the Ghanaian public was with regards to the policy, whether they supported the policy, and their thoughts about how well the policy has been enforced and its long-term impact. Participants' attitudes towards fatty meat in general, as well as preference for and consumption of different meat types were also assessed.

\section{Sample size}

The sample size equation [Sample size $=\mathrm{Z}_{1-\boldsymbol{\alpha} / 2}{ }^{2} \mathrm{p}(1-\mathrm{p}) / \mathrm{d}^{2}$ ] [21] for cross sectional study (qualitative variable) was used to determine the sample size. Where, $\mathrm{Z}_{1-\alpha / 2}$ is standard normal variable at $5 \%$ type 1 error $(p<0.05)$, which is $1.96, \mathrm{p}$ is the expected proportion of participants aware of the restriction set at half of the population, $50 \%$ or 0.5 (as this was unknown) and $d$ is the precision/absolute error of $5 \%$ and at type 1 error of $5 \%$. Using the above formula, a sample size of 384 was calculated for the study, although data was eventually collected from 377 participants.

\section{Participants recruitment}

Three hundred and seventy-seven (377) participants, aged 18 years and above living in 9 suburbs (Atonsu Agogo, Anloga, Atonsu, Ayigya, Ayeduase, Ayeduase Newsite, Kotei, Kwadaso, and Oforikrom) of Kumasi were recruited by final year undergraduate students from the Kwame Nkrumah University of Science and Technology (KNUST) trained for this study. The suburbs, although purposively selected, were all big towns in Kumasi, and were chosen to give a good spread of participants from the Metropolis. In each suburb, study enumerators went from house-to-house to recruit participants. Participants were recruited on first-come-firstservice basis from house-to-house visits until at least 30 participants were recruited. The selection of houses was not systematic nor random since enumerators could enter any house upon entering the suburb and move to the next house afterwards. If a house had no adult available at the time of visit, the next house was entered. The direction of the next house from the preceding one was completely dependent on the enumerators. For each house entered, adults living in the house got the aims, objectives and other information about the survey explained to them, after which they were asked to volunteer. Only one adult was chosen from each house and it was usually the first person who volunteered to take part. Apart from the 30 participants selected from each suburb of the 9 suburbs by house-to-house visits, some participants were met on the road side in the suburbs and asked to participate. Some churches and workplaces were visited and people asked to volunteer until the required sample size was attained.

\section{Data collection}

A validated structured questionnaire was adapted for this study, which had been developed and used for assessing consumer responses to the turkey tail ban in Samoa [18]. The questionnaire was interviewer administered and apart from personal information, had close-ended questions regarding awareness of the policy, support for the policy, attitude and preference for meat types, comparing imported versus local meat types. Open-ended questions were used to assess participants' perception of the outcome and impact of the restriction. The questionnaire also included a Food Frequency Questionnaire (FFQ). The FFQ used was based on a standard layout for FFQs but was adapted to suit the local food (meat and meat products) environment of Kumasi. The FFQ used had 7 meat types (local versus imported beef, chicken, turkey tail, pork, mutton, goat meat and processed meat) and 5 options for frequency of consumption: Weekly, Fortnightly, Monthly, Occasionally and Never. The entire questionnaire and study instruments were pretested by interviewers among adults living near the University campus as part of training for data collection. The study instruments were amended following the pretest.

Assessment of body composition and blood pressure were done using the OMRON body composition analyser and a digital sphygmomanometer respectively. For the body composition assessment, participants' height in centimeters were first measured using a SECA stadiometer and then the heights, age and gender were entered into the analyser for the assessment of body composition. The purpose of this was to know the status of these parameters among participants. 


\section{Data analysis}

The data were analysed using SPSS software, version 17.0.1 (SPSS Inc., Chicago IL, USA). Statistical significance was set at $p<0.05$ for all analyses. Data from the food frequency questionnaire were used to describe and compare consumption pattern of imported versus local meat types and products among the participants. All other analyses were done using simple frequencies and percentages and presented as tables.

\section{Results}

\section{Description of respondents}

Of the 377 study participants, 140 (37\%) were males and 237 (63\%) were females (Table 1). A larger proportion of the respondents (72\%) were within 18-35 years age range, followed by $36-50$ years $(23 \%)$ and above 50 years old (5\%). There were varied occupational activities among the respondents but just over a third were labourers, $18.3 \%$ were traders and $10.9 \%$ were teachers. Mean BMI of the respondents was $25.4 \mathrm{~kg} / \mathrm{m}^{2}$, and mean body fat was $30.4 \%$, while mean systolic and

Table 1 Personal information of respondents

\begin{tabular}{|c|c|c|}
\hline Variable & Frequency & Percentage \\
\hline \multicolumn{3}{|l|}{ Age (years) } \\
\hline $18-35$ & 272 & 72.1 \\
\hline $36-50$ & 86 & 22.8 \\
\hline$>50$ & 19 & 5 \\
\hline \multicolumn{3}{|l|}{ Gender } \\
\hline Male & 140 & 37.1 \\
\hline Female & 237 & 62.9 \\
\hline \multicolumn{3}{|l|}{ Occupation } \\
\hline Trader & 69 & 18.3 \\
\hline Farmer & 8 & 2.1 \\
\hline Teacher/lecturer & 41 & 10.9 \\
\hline Health worker & 19 & 5 \\
\hline Labourer & 129 & 34.2 \\
\hline Office worker & 28 & 7.4 \\
\hline Student & 21 & 5.6 \\
\hline Unemployed & 32 & 8.5 \\
\hline Engineer & 6 & 1.6 \\
\hline Sales girl/boy & 14 & 3.7 \\
\hline Security personnel & 1 & 0.3 \\
\hline Drivers & 6 & 1.6 \\
\hline \multicolumn{3}{|l|}{ Body Composition } \\
\hline $\mathrm{BMI}$ & 25.4 & 0.4 \\
\hline Percentage Body Fat & 30.43 & 0.95 \\
\hline Visceral Fat & 6.25 & 0.45 \\
\hline Percentage Muscle mass & 31.35 & 0.5 \\
\hline
\end{tabular}

diastolic blood pressure of participants were 123.5 and $77.25 \mathrm{mmHg}$ respectively.

\section{Public awareness and perception about restriction}

Two hundred and twenty-two (59\%) respondents were aware of the restrictions on fatty meat importation (Table 2). Of those aware of the restriction, majority heard it from radio broadcast 101 (46\%), Television (20\%) and word of mouth (10\%). Close to $13 \%$ heard from two of the named avenues and about $3 \%$ from all three avenues. Over half of the respondents (57\%) thought the public were not aware of the restrictions. Most of the respondents (whether aware or not aware) $(306,81.2 \%)$ thought the restrictions are necessary and/or supported the restrictions. Of these, the top reason given was that fatty meat causes diseases and health problems (50\%) and that the restriction is needed to check meat quality $(22.5 \%)$. A small proportion said the restriction was good for the nation (7.2\%) and is needed help to protect local industry (9.7\%). Of the $38(10.1 \%)$ respondents who thought the restrictions were

Table 2 Perception, awareness and enforcement of restrictions

\begin{tabular}{|c|c|c|}
\hline$N=377$ & Frequency & Percentage \\
\hline \multicolumn{3}{|c|}{ Are you aware of the restriction \& is the public aware? } \\
\hline Yes & 222,147 & $58.9,39$ \\
\hline No & 155,215 & $41.1,57$ \\
\hline \multicolumn{3}{|l|}{ How did you hear about the restriction? } \\
\hline TV & 45 & 20.1 \\
\hline Radio & 101 & 46.1 \\
\hline Newspaper & 7 & 3.1 \\
\hline Word of mouth & 23 & 10.3 \\
\hline Other means & 5 & 2.2 \\
\hline More than one channel & 38 & 17.1 \\
\hline \multicolumn{3}{|c|}{ Do you think the restriction is being enforced or necessary? } \\
\hline Yes & 55 & 14.9 \\
\hline No & 308 & 81.7 \\
\hline Don't know & 14 & 3.7 \\
\hline \multicolumn{3}{|l|}{ Do you think the restriction is necessary? } \\
\hline Yes & 306 & 81.2 \\
\hline No & 38 & 10.2 \\
\hline Don't know & 32 & 8.5 \\
\hline \multicolumn{3}{|l|}{ Why is the restriction necessary? $(N=236)$} \\
\hline $\begin{array}{l}\text { Fatty meat causes diseases and health } \\
\text { problems }\end{array}$ & 118 & 50 \\
\hline Restriction will help reduce deaths & 14 & 5.9 \\
\hline Restriction good for the nation & 17 & 7.2 \\
\hline Needed to promote local industry & 23 & 9.7 \\
\hline $\begin{array}{l}\text { Imported meat unwholesome due to } \\
\text { prolong storage }\end{array}$ & 11 & 4.7 \\
\hline To check the quality of meat & 53 & 22.5 \\
\hline
\end{tabular}


not necessary, most (87.5\%) said there was no information about the need for restriction, others said local meat is expensive (28.6\%), while others asserted that the government should not control what people choose to eat (20\%). Less than $15 \%$ felt the restrictions were being enforced.

\section{Respondents' attitude towards fatty meat}

From Table 3, over two-thirds of respondents (253 people) said they consider the fat content of the meat they buy. Of these, the reasons given were that fat causes health problems $(57.3 \%$ or $38.5 \%$ of total survey population), personal dislike (17.4\%), it ensures good nutrition (11.5\%), causes obesity and stroke $(11.1 \%)$ and helps prevent lipid disorders (2.8\%). Among those who did not consider the fat content of the meat they buy (124, $32.9 \%)$, the reasons given included ignorance (32.3\%), indifference $(28.2 \%)$, fat tastes good $(12.9 \%)$, preference (13.7\%) and affordability (7.2\%).

\section{Access, availability and preference: Local versus imported} meat and products

Comparing imported versus local meat and products, $56.5 \%$ participants said the former were more available, but $42.4 \%$ reported the opposite. However, over twothirds of participants reported that imported meat and products were cheaper than the local ones (Table 4). For all the meat types, with the exception of pork, participants predominantly preferred the local than the imported cuts. Reasons given for preference of local meat types were better taste (41\%), access/cost (20.7\%), freshness (13.3\%), healthiness (18.3\%) and religion (13.3\%).

Table 3 Respondents general attitude towards fatty meat

\begin{tabular}{lcl}
\hline$N=377$ & Frequency & Percentage \\
\hline $\begin{array}{lll}\text { Do you consider the fat content of the meat you buy? } \\
\text { Yes }\end{array}$ & 253 & 67.1 \\
No & 124 & 32.9 \\
Why do you consider the fat content of meat you buy? & \\
Fat causes health problems & 145 & 38.5 \\
Fat leads to obesity/stroke & 28 & 7.4 \\
Personal dislike & 44 & 11.7 \\
For good nutrition & 29 & 7.7 \\
To prevent lipid disorders & 7 & 1.9 \\
Why don't you consider the fat content of meat you buy? & \\
Hunger & 9 & 2.4 \\
Limited options & 7 & 1.9 \\
Indifference & 35 & 9.3 \\
Fat tastes good & 16 & 4.2 \\
Ignorance & 40 & 10.6 \\
Preference & 17 & 4.5 \\
\hline
\end{tabular}

Table 4 Availability, access and preference for imported versus local imported meat

\begin{tabular}{ll}
\hline Question & Percentage \\
\hline Which is more available? & 42.4 \\
Local meat and meat products & 56.5 \\
Imported meat and meat products & 1.1 \\
Missing & \\
Which is cheaper? & 27.9 \\
$\quad$ Local meat & 69.5 \\
$\quad$ Imported meat & 2.7 \\
Don't know & \\
Preference & \\
Beef, chicken, pork, mutton, goat & $83.6,69.5,33.7,58.4,82.6$ \\
$\quad$ Local & $7.2,27.3,18.8,2.1,0.8$ \\
Imported & $10.2,3.2,47.5,39.5,16.4$ \\
$\quad$ No preference & \\
\hline$N=377$ &
\end{tabular}

\section{Consumption of local versus imported meat and meat products}

As shown in Table 5, imported chicken was more regularly (more than once a month) consumed than local chicken (50\% versus $27.5 \%$ ). Imported pork and processed meat were also more regularly consumed than the local versions. The meats for which local production was more commonly consumed than the imported versions were beef (50\% versus $18.6 \%$ ), goat meat $(41.5 \%$ versus $27.3 \%)$ and mutton (18\% versus

Table 5 Frequency of consumption of local versus imported meat and meat products

\begin{tabular}{llll}
\hline Food item & $\begin{array}{l}\text { More than } \\
\text { once a month }\end{array}$ & Once a month & $\begin{array}{l}\text { Occasional } \\
\& \text { never }\end{array}$ \\
\hline Imported beef & 18.6 & 7.2 & 77 \\
Local beef & 50 & 11.9 & 37.7 \\
Imported chicken & 50 & 13.5 & 38.4 \\
Local chicken & 27.5 & 14.1 & 57.9 \\
Imported turkey tail & 2.4 & 1.3 & 96.4 \\
Local turkey tail & 2.2 & 1.3 & 96.6 \\
Imported pork & 16.0 & 5 & 79 \\
Local pork & 14.4 & 6.1 & 79.6 \\
Imported mutton & 7.4 & 4.5 & 88.1 \\
Local mutton & 18.3 & 8 & 73.7 \\
Imported goat meat & 10.1 & 7.2 & 83.1 \\
Local goat meat & 41.5 & 13.8 & 54.6 \\
Imported processed meat & 27.3 & 12.2 & 60.5 \\
Local processed meat & 19.9 & 7.4 & 75.9 \\
\hline
\end{tabular}

The FFQ used had 5 categories of frequencies. In the analysis, weekly and fortnightly were combined into one category labelled more than once a month, and occasionally and never also combined into one category 
$7 \%)$. Turkey tail was hardly consumed $(<3 \%$ consumed more than once a month).

\section{Perceptions of the effects of the fatty meat restrictions}

As shown in Table 6, a third of participants were not sure of the outcome of the restriction, 23.6\% thought it had had no effect whereas $19.2 \%$ thought it had reduced diseases and improved quality of life. Very few (3.7\%) said the restriction had reduced importation, caused unemployment for importers (4.2\%) or had led to high cost of living due to high cost of local meat (3.7\%). However, when asked about the long-term effect of the restriction, close to $60 \%$ said it would improve health, prevent disease and/or reduce death. Just over $10 \%$ had no idea or thought there would be little to no effect. Whereas some participants said there would be better business and employment for local meat industries (8.3\%), others said it would create unemployment for importers (5\%).

\section{Discussions}

Majority of the participants in this study were between 18 and 35 years old. The gender, age and occupational

Table 6 Participants perception of the outcome, impact and long-term effects of the restriction

\begin{tabular}{lll}
\hline Question & Frequency & Percentage \\
\hline What has been the outcome of the restriction? & 89 & 23.6 \\
No to little effect & 14 & 3.7 \\
Reduction on importation & 122 & 32.4 \\
Not sure & 16 & 4.2 \\
Caused unemployment for importers & 10 & 2.7 \\
People avoid fatty meat now & 13 & 3.4 \\
Local farmers are producing more & 73 & 19.4 \\
Reduced diseases/improved quality of life & 23 & 6.1 \\
Poor education about the ban & 3 & 0.8 \\
Unhygienic packaging of local meat & 14 & 3.7 \\
Expensive local meat/high cost of living & 14 \\
What do you think will be the longer-term effect of the restriction? \\
It will improve health, prevent disease & 138 & 59.4 \\
and/or reduce death & & \\
No idea/no effect & 43 & 11.4 \\
Importation will reduce & 16 & 4.2 \\
Employment for local meat sellers & 13 & 3.4 \\
Unemployment for importers & 15 & 4.0 \\
Less tax revenue for government & 2 & 0.5 \\
Affect Ghana's export business & 1 & 0.3 \\
Local meat will be expensive & 8 & 2.1 \\
Policy cannot be strictly enforced & 19 & 5.1 \\
Higher patronage of local meat & 21 & 5.6 \\
Higher cost of living & 10 & 2.7 \\
\hline
\end{tabular}

distribution of participants reflect the average adult Ghanaian. The average BMI puts the females as overweight and the males as normal weight. Although the females had a higher proportion of body fat, the fact that visceral fat in the males was higher reflect a higher tendency of intra-abdominal obesity in the males. Mean blood pressures were also higher in the males although both systolic and diastolic blood pressures were within the normal ranges for both gender. Combined, the study participants represented a generally healthy adult Ghanaian population.

The findings suggest that respondents' awareness regarding Ghana's trade-related standards policy that restricts meat importation based on fat content remains fairly high and attitudes towards the restriction is positive, over two decades after the ban was implemented. About half of those interviewed were aware of the restrictions, although more than half thought the public was not aware and majority felt enforcement done is ineffective. There does not seem to be a lot effort to raise public awareness about this policy. A search of newspaper coverage of the restrictions in the early 1990s, when the restrictions were passed, showed little coverage on the restrictions in general and the ban on turkey tail. The relatively high awareness, however, may also reflect regular enforcement efforts, which included destruction of 1452 cartons of turkey tail imports in Kumasi in 2010 [22]. The fact that majority (60\%) thought the restriction in the long-term could improve health, prevent disease and reduce death was reassuring.

The findings also showed a good attitude of participants towards fatty meat and this may be indicative of a general good attitude towards healthy eating. It did seem that there has been some effort to sensitize the public on the effect of high fat intake and diet related chronic diseases by the level of knowledge/perception of these respondents. Also, close to $70 \%$ said they considered the fat content of the meat they bought and all seemed to know the negative effects of fat on health. This good attitude could also be due to the increasing trends of non communicable diseases in the country [4], which are associated with the diet and lifestyles of people [23] and which have gained some attention in the country. However, it was not clear whether awareness of these issues had increased over time because of lack of earlier studies to compare our findings.

Among the meat types, half of the population consumed local beef compared to less than $20 \%$ consuming the imported version, while half of the population consumed imported chicken regularly compared to less than a third consuming the local version. The disparity between the consumption of beef and chicken is mainly because imported chicken is commonly available and cheaper than its local counterpart, while local beef is 
more commonly available and cheaper than its imported counterpart. The very low consumption of turkey tails reported in this survey (less than 3\%) indicates that the restrictions have been effective in significantly reducing availability and consumption of turkey tail, which was banned as a result of the restrictions. This is contrary to perception of respondents' that the restriction is not well enforced. For all the meat types, with the exception of pork, participants predominantly preferred the local to the imported. The reasons given for the preference were better taste, access/cost, freshness, healthiness and religion. These factors, among others are known to influence people's food habits and choice [24]. These factors seemed to be interwoven in their effect on preference and consumption. Irrespective of whether it is local or imported, some participants chose their meat based on health reasons and for this group, perception as to which version is more or less healthy informed their preference. But looking at the interplay of the factors, it seemed that availability and cheapness were the ultimate determinants and drivers of consumption of meat products. Majority of participants said imported meat products were more available and cheaper but our findings showed the vast majority of participants interviewed preferred the local to the imported meat types due to better taste and healthiness. Therefore, the fact that consumption of imported chicken, pork and processed meat were higher than the local types, although the local types were preferred suggests that availability/cheapness drove consumption, and confirms the worry about the food environment becoming more obesogenic [25]. This is why public health policies which restrict access to unhealthy diet, thereby making the food environment healthier as part of a package of interventions for prevention of non communicable diseases are recommended $[14,15]$.

This study could not evaluate the impact of the fatty meat restriction on consumption of meat products, since data on consumption before the restriction was not available. Little is known about the contribution of fatty meat to the Ghanaian diet. Moreover, although the participants of this study were all adults, majority were between 18 and 35 years old, and thus a large proportion were not old enough to share their experience before and after the implementation of the policy, nor was it possible to evaluate the impact of the policy on their consumption of meat types. However, the policy was passed in response to concerns that fatty meat, especially turkey tail and chicken feet were commonly imported and available on the market. The policy analysis paper earlier published explains the contexts and content of the policy [20]. The overall effect of the ban has been to reduce availability of specific 'low quality' meats in the Ghanaian food supply, namely turkey tails and chicken feet [20]. It was useful to understand the landscape
20 years after the policy implementation. Is fatty meat still a problem? What is the nutritional situation in Ghana now? Is it possible that this policy has helped to minimize this aspect of the nutrition transition? It was expected that the reduction in availability may have influenced consumption of fatty meat products. The very low consumption of turkey tail from the present study findings supports this.

\section{Conclusion}

In conclusion this study showed appreciable awareness among Ghanaian adults regarding Ghana's innovative trade policy, which restricts importation of meat and meat products based on fat content, two decades after implementation. There was a general good knowledge and positive attitude towards the restrictions and diet for health, reflected in preference for local meat types, which were considered to be healthier, tastier and fresher. However, consumption was driven more by availability and cheapness. Most respondents supported the restriction and were positive about the long-term positive effect of this policy on health and nutrition but thought the policy was not well enforced. There is therefore a call to improve enforcement and to implement other public health policies in order to make the food environment healthier and contribute towards preventing diet-related chronic diseases, which are on the rise in the country.

\section{Abbreviations}

BMI: Body Mass Index; CEPS: Customs Excise and Preventive Services; CHD: Coronary Heart Disease; CHRPE: Committee on Human Research and Publications Ethics; CVD: Cardiovascular Disease; FFQ: Food Frequency Questionnaire; KATH: Komfo Anokye Teaching Hospital; KNUST: Kwame Nkrumah University of Science and Technology; SPSS: Statistical Package for Social Sciences; USA: United States of America; WHO: World Health Orgnisation

\section{Acknowledgements}

Not applicable

\section{Funding}

The study was partly funded by University of Sydney School of Public Health Academic Development Scheme, held by Dr. Anne Marie Thow. The remaining funding was provided by KNUST.

\section{Availability of data and materials \\ The datasets used and/or analysed during the current study available from the corresponding author on reasonable request.}

\section{Authors' contributions}

The study was conceived and designed by AMT and RAA. AMT, RAA, KO, VPA and LM did data collection, analyses and interpretation. Manuscript was drafted by RAA and critically reviewed by all authors. All authors read and approved the final manuscript.

\section{Competing interest}

The authors declare that they have no competing interests.

\section{Ethics approval and consent to participate}

This study was approved by the Committee on Human Research Publication and Ethics (CHRPE) of the School of Medical Sciences, Kwame Nkrumah University of Science and Technology (KNUST) and the Komfo Anokye 
Teaching Hospital (KATH), Kumasi. Participation in the study was voluntary and informed consents were obtained from all participants.

\section{Consent for publication}

Not applicable.

\section{Publisher's Note}

Springer Nature remains neutral with regard to jurisdictional claims in published maps and institutional affiliations.

\section{Author details}

${ }^{1}$ Department of Biochemistry and Biotechnology, College of Science, Kwame Nkrumah University of Science and Technology, Private Mail Bag, University Post Office, Kumasi, Ghana. ${ }^{2}$ Menzies Centre for Health Policy, School of Public Health, University of Sydney, Camperdown, Australia.

Received: 17 June 2017 Accepted: 23 January 2018

\section{Published online: 05 February 2018}

\section{References}

1. WHO. World Health Organisation Childhood nutrition and progress in implementing the International Code of Marketing Breast milk substitutes (document A55/14). Geneva: WHO; 2002.

2. Keyhani D, Kargarfard M, Sarrafzadegan N and Sadeghi M. Autonomic function change following a supervised exercise program in patients with congestive heart failure. ARYA Atheroscler. 2013; 9(2): 150-156. PMCID: PMC3653242.

3. World Health Organization, 2012. Cardiovascular diseases. Geneva: WHO. 2012 http://www.who.int/topics/cardiovascular_diseases/en/. Accessed 13 June 2012

4. Aikins AD. Ghana's neglected chronic disease epidemic: a developmental challenge. Ghana Medical Journal. 2007;41(4): 154-159. PMCID: PMC2350116.

5. Berg CM, Lappas G, Strandhagen E, et al. Food patterns and cardiovascular disease risk factors: the Swedish INTERGENE research program. Am J Clin Nutr. 2008:88(2):289-97.

6. Bourne LT, Lambert EV, Steyn K. Where does the black population of South Africa stand on the nutrition transition? Public Health Nutr. 2002;5:157-62. https://doi.org/10.1079/PHN2001288.

7. Slattery ML, Boucher KM, Caan BJ, et al. Eating patterns and risk of colon cancer. Am J Epidemiol. 1998;148(1):4-16. https://doi.org/10.1093/aje/148.1.4.

8. Hu FB, Rimm EB, Stampfer MJ, et al. Prospective study of major dietary patterns and risk of coronary heart disease in men. Am J Clin Nutr. 2000; 72(4):912-21.

9. Agyei-Mensah S, Aikins A d-g. Epidemiological transition and the double burden of disease in Accra, Ghana. J Urban Health. 2010;87(5):879-97.

10. Government of Ghana. Government of Ghana New policy on noncommunicable diseases [Online]. Accra: Ghana Government Portal; 2012.

11. Nugent R. Chronic diseases in developing countries: health and economic burdens. Ann N Y. Acad Sci. 2008;1136:70-9.

12. Popkin B. Technology, transport, globalization and the nutrition transition. Food Policy. 2006;31:554-69.

13. Thow AM. Trade liberalisation and the nutrition transition: mapping the pathways for public health nutritionists. Public Health Nutr. 2009;12(11):2150-8.

14. Hawkes C, Jewell J, Allen K. A food policy package for healthy diets and the prevention of obesity and diet-related non-communicable diseases: the NOURISHING framework. Obes Rev. 2013:14:159-68.

15. Hawkes C, Thow AM, Downs S, Ghosh-Jerath S, Snowdon W, Morgan E, Thiam I, Jewell J. Leveraging agriculture and food systems for healthier diets and noncommunicable disease prevention: the need for policy coherence. Expert paper for the second international conference on nutrition. Food and Agriculture Organization of the United Nations: Rome; 2013.

16. Buse, U. In Cameroon, globalization's losers fight back and win. Spiegel Online International; 2007.

17. Gewertz DB, Errington F. Cheap meat: flap food nations in the Pacific Islands. Chapter 6: Pacific Island flaps. Berkeley: University of California Press; 2009.

18. Thow AM, Swinburn BS, Colagiuri S, et al. Trade and food policy: case studies from three Pacific Island countries. Food Policy. 2010;35:556-64.

19. UNCTD (United Nations Conference on Trade and Development). Trade Analysis and Information System (2002) Country Notes - Ghana. Geneva: UNCTAD.

20. Thow AM, Annan RA, Mensah L, Chowdhury SN. Development, implementation, and outcome of standards to restrict fatty meat in the food supply and prevent NCDs: learning from an innovative trade/food policy in Ghana. BMC Public Health. 2014;14:249.

21. Charan J, Biswas T. How to calculate sample size for different study designs in medical research? Indian Journal of Psychological Medicine. 2013;35(2): 121-6. https://doi.org/10.4103/0253-7176.116232

22. Anonymous: 1452 cartons of turkey tail destroyed in Kumasi. In: Daily Graphic. Wednesday 28 April 2010 edn. Accra; 2010.

23. Afoakwah AN, Owusu WB. The relationship between dietary intake, body composition and blood pressure in male adult miners in Ghana. Asian journal of. Clin Nutr. 2011;3(1):1-13.

24. Rolfes SR, Pinna K, Whitney E. Understanding normal and clinical nutrition. 8 edition. Wadsworth: Brook Cole; 2009.

25. Mustajoki P. Obesogenic food environment explains most of the obesity epidemic. Duodecim. 2015;131(15):1345-52.

\section{Submit your next manuscript to BioMed Central and we will help you at every step:}

- We accept pre-submission inquiries

- Our selector tool helps you to find the most relevant journal

- We provide round the clock customer support

- Convenient online submission

- Thorough peer review

- Inclusion in PubMed and all major indexing services

- Maximum visibility for your research

Submit your manuscript at www.biomedcentral.com/submit
Biomed Central 